Important Note: This pre-print has been peer-reviewed and published at Social Science \& Medicine. We advise readers to consult and cite the latest version of this work, available at https://doi.org/10.1016/j.socscimed.2021.114611

\title{
What drives beliefs in COVID-19 conspiracy theories? The role of psychotic-like experiences and confinement-related factors
}

Simão Ferreira ${ }^{1}$, Carlos Campos ${ }^{123}$, Beatriz Marinho ${ }^{1}$, Susana Rocha ${ }^{4}$, Eduardo FonsecaPedrero $^{5}$, Nuno Barbosa Rocha ${ }^{1 *}$

${ }^{1}$ Center for Rehabilitation Research, School of Health, Polytechnic Institute of Porto, Porto, Portugal

${ }^{2}$ Laboratory of Neuropsychophysiology, Faculty of Psychology and Educational Sciences, University of Porto, Portugal

${ }^{3}$ Faculty of Medicine, University of Porto, Porto, Portugal

${ }^{4}$ Polytechnic Institute of Porto, Porto, Portugal

${ }^{5}$ University of La Rioja, Spain

*Corresponding Author:

Prof. Nuno Barbosa Rocha

nrocha@ess.ipp.pt

\begin{abstract}
The COVID-19 pandemic is a worldwide threat to public health and the global economy. The climate of fear and uncertainty associated with the pandemic has fostered the emergence of a wide-range of COVID-19 conspiracy theories that has the potential do shape public opinion and hinder the effective dissemination of valid information. Beliefs in conspiracy theories has been associated with maladaptive personality traits such as schizotypy and paranoia, as well as other non-psychotic psychological characteristics (e.g., social isolation, stress). The current study aimed to examine the association between beliefs in COVID-19 conspiracy theories and psychotic-like experiences within the community, while also addressing the role of sociodemographic information, psychological outcomes (e.g., stress, affective states) and other pandemic-related factors (e.g., confinement conditions/behaviors). Our results suggest that psychotic-like experiences are associated with beliefs in COVID-19 conspiracy theories, particularly perceptual abnormalities and persecutory ideation. Moreover, increased healthrelated concerns and reduced education levels also seem to be liability factors for these conspiracy beliefs. These results add important insights into how the adherence to illogical and erroneous disease-related arguments may be contingent to proneness to psychotic-like experiences. COVID-19 conspiracy theories are yet another major challenge that governments and policy makers must contemplate when defining strategic directions to manage the current and future pandemics.
\end{abstract}

Keywords: COVID-19; pandemic; confinement; conspiracy theories; psychosis 


\section{Introduction}

COVID-19 is a potentially serious acute respiratory disease caused by the new SARSCOV-2 coronavirus, which first appeared in Wuhan (China) at the beginning of December 2019. On the $11^{\text {th }}$ of March 2020, the World Health Organization (WHO) declared this disease as a pandemic, due to the alarming transmission rates and the lack of action, with no vaccines or biologic therapies available at that time proven to be efficient to fight the virus[1,2]. With the exponential increase in the number of affected individuals, COVID-19 became a significant threat to public health and the global economy, which lead to the introduction of diverse contention measures, as a strategy to fight the virus propagation $[3,4]$.

According to WHO, government-mandated lockdown and its impact on people's habits and routines may lead to an increase in the prevalence of depressive disorders, anxiety, and post-traumatic stress [5-10]. Generally, these disorders last for a long time and can be exacerbated or first experienced due to the uncertainties caused by the lack of knowledge regarding the disease, as well as due to the lack of transparency by the government and health professionals [11-16].

In the case of the COVID-19 pandemic, and unlike other pandemics in the past, there was a constant dissemination of sensationalist reports regarding the new coronavirus, mostly because of social media, thus intensifying public doubts and raising fear, panic, and distrust [17-22]. This climate of uncertainty leaves an open door for alternative explanations of pandemic-related events, ultimately leading to the emergence of conspiracy theories. These result from the actions of a wide, insidious, and efficient international conspiratorial network, conceived to perpetrate acts which nature is harmful, intentionally deceiving and manipulating the public opinion for its self-benefit [23].

Beliefs in conspiracy theories are related to maladaptive personality traits, schizotypy, and paranoia [24,25]. Previous evidence suggests that psychotic experiences are positively related with the receptivity to conspiracy theories and ontological fantastic stories, as these experiences potentiate the development of bizarre or abnormal thoughts and nonconventional logic, which might be associated with impaired perceptive decision-making as well as causal, probabilistic, and logical thinking [26-30]. Psychotic-like experiences are reduced forms of hallucinatory perceptions and illusory beliefs that are similar to the symptoms of psychotic disorders, yet not reaching the limit of clinical significance, considering its lower intensity and persistency, not being associated with clear incapacity and significant psychological suffering [31-35]. Recent studies emphasize that these experiences are present on a substantial proportion of the general population, with a prevalence of approximately $7 \%$, from which $80 \%$ are transitory psychotic experiences and $20 \%$ represent persistent experiences [36,37]. It is important to highlight that from the individuals who experience persistent psychotic experiences, 7\% develop a psychotic disorder, with a transition annual rate below $1 \%$ [37]. Thus, understanding the interaction between psychoticlike experiences in community-samples and beliefs in conspiracy theories may be critical to tackle the ongoing growth of conspiracy theory believers, which truly may hinder societal efforts to manage the pandemic (including the generalization of treatment and vaccines once they are ready). 
Other non-psychotic psychological characteristics have also been linked to beliefs in conspiracy theories, namely the lack of self-esteem, social isolation, sleep privation, and a higher susceptibility to stress and anxiety, jointly with the feelings of uncertainty, uneasiness, and helplessness [38-44]. The confinement experience during the pandemic was also largely dependent on additional factors such as housing conditions, caregiver role, health-related concerns, among others. The pandemic produced significant changes in work-related variables, as several people had changes in their monthly income or started teleworking during this period. Thus, it is important to understand how confinement-related experiences and behaviours may have also played a role in COVID-19 conspiracy theories beliefs.")

Furthermore, measures related to confinement can also contribute to the appearance of psychotic experiences [45-47]. This interference is corroborated by social networks and the reduced frequency of visual contact presented by individuals who suffer from psychotic disorders, before the appearance of the disease $[48,49]$.

Additionally, several researchers demonstrated that psychotic experiences are also a risk indicator for the appearance of mental disorders, such as depressive disorders, anxiety, post-traumatic stress, and personality [50,51] being associated with risk behaviors, such as attempted suicides [52,53], psychological suffering [54], functional involvement [55], chronic physical conditions [56], as well as a higher need for psychiatric intervention and higher mortality risk [57]. One of the main goals of this study consists in verifying the association between the belief in conspiracy theories and psychotic-like experiences. It is expected that individuals who present psychotic-like experiences are more prone to believe in conspiracy theories.

Hence, besides looking at the link between psychotic-like experiences and beliefs in conspiracy theories, we should also explore how other moderating variables may increase the likelihood to develop these beliefs.

The current study aims to examine the association between beliefs in COVID-19 conspiracy theories and psychotic-like experiences within the community, while also addressing the role of other contributing variables such as sociodemographic information (sex, age, education), psychological outcomes (e.g., stress, affective states) as well as other pandemic-related factors (e.g., isolation conditions, health concerns).

\section{Results}

\section{Sociodemographic Variables and COVID-19 Conspiracy Theories}

Sample characteristics are described in Table 1. Sex was not associated with differences on COVID-19 Conspiracy Theories Beliefs, $t$ (436) $=0.031, p=0.969$, MD 99\% CI [-2.886, 3.321], as both males and females displayed quite similar scores $(\mathrm{M}=21.51$, SD $=9.77$ vs. $\mathrm{M}=21.54, \mathrm{SD}=10.38$, respectively). COVID-19 Conspiracy Theories Beliefs were negatively and moderately associated with education years, $r(436)=-0.203, p<0.001$, 99\% CI [-0.328, -0.069]. There was no significant correlation between COVID-19 Conspiracy Theories Beliefs and age, $r(436)=0.076, p=0.114,99 \%$ CI $[-0.061,0.218]$. 


\section{Confinement Behaviors/Beliefs and COVID-19 Conspiracy Theories}

Although participants that reported not being in confinement $(n=109)$ were not included in the full analysis, it was still relevant to compare them with participants in confinement $(\mathrm{n}=438)$ regarding COVID-19 Conspiracy Theories Beliefs. There were no significant differences between both groups, $t(545)=1.593, p=0.108$, MD 99\% CI [-1.258, 5.351], although descriptive statistics suggest that participants in confinement displayed lower scores in the COVID-19 Conspiracy Theories Beliefs Questionnaire in comparison to non-confiners $(\mathrm{M}=21.53, \mathrm{SD}=10.24$ vs. $\mathrm{M}=23.50, \mathrm{SD}=11.37$, respectively).

Results regarding the role of confinement-related behaviors/beliefs in COVID-19 Conspiracy Theories Beliefs are presented in Table 2. There was a statistically significant positive and small correlation between COVID-Related Health Concerns and COVID-19 Conspiracy Theories Beliefs, $r(436)=0.158, p=0.003,99 \%$ CI [0.012, 0.292]. Moreover, there was a marginally significant difference in COVID-19 Conspiracy Theories Beliefs regarding leaving the house during the confinement, $t(436)=-2.218, p=0.025$, MD 99\% CI [-6.982, 0.638]. More specifically, participants that left their house during the confinement displayed higher scores in the COVID-19 Conspiracy Theories Beliefs Questionnaire in comparison to participants that reported not leaving $(\mathrm{M}=21.75, \mathrm{SD}=10.37 \mathrm{vs.} \mathrm{M}=18.48$, $\mathrm{SD}=7.56$, respectively). Finally, there was also a statistical trend for a small positive association between COVID-19 Conspiracy Theories Beliefs and smoking frequency during confinement, $r(436)=0.129, p=0.024,99 \%$ CI [-0.014, 0.273].

[INSERT TABLE 2 HERE]

\section{Confinement Conditions and COVID-19 Conspiracy Theories}

Results regarding the association between confinement conditions and COVID-19 Conspiracy Theories Beliefs are presented in Table 3. There were no significant associations in any of the collected variables.

[INSERT TABLE 3 HERE]

\section{Work and Finance-Related Variables and COVID-19 Conspiracy Theories}

Findings addressing the role of work/finance related variables in COVID-19 Conspiracy Theories Beliefs are presented in Table 4. There was a statistically significant small and positive association between pandemic-related financial concerns and COVID-19 Conspiracy Theories Beliefs, $r(436)=0.189, p<0.001,99 \%$ CI [0.057, 0.328]. Furthermore, there was a marginally significant difference in COVID-19 Conspiracy Theories Beliefs regarding pandemic-related budget reductions, $t(436)=-2.174, p=0.036$, MD 99\% CI [- 
4.552, 0.462]. More specifically, participants that experienced budget reductions displayed higher scores in the COVID-19 Conspiracy Theories Beliefs Questionnaire in comparison to participants that did not $(\mathrm{M}=22.68, \mathrm{SD}=10.32$ vs. $\mathrm{M}=20.57, \mathrm{SD}=10.09$, respectively).

Finally, there were also marginal differences in COVID-19 Conspiracy Theories Beliefs between participants that transitioned to telework and those who did not, $t(240)=$ $2.120, p=0.036$, MD 99\% CI [-0.507, 7.123]. Teleworkers displayed less beliefs in COVID19 Conspiracy Theories in comparison to participants that did not work from home $(\mathrm{M}=$ $20.67, \mathrm{SD}=8.67$ vs. $\mathrm{M}=23.74, \mathrm{SD}=11.20$, respectively).

[INSERT TABLE 4 HERE]

\section{Psychotic-Like Experiences, Psychological Distress and COVID-19 Conspiracy Theories}

Results addressing how clinical measures and psychological distress is related to COVID-19 Conspiracy Theories Beliefs are presented in Table 5. There was a statistically significant moderate and positive association between CAPES Total score and COVID-19 Conspiracy Theories Beliefs, $r(436)=0.271, p<0.001,99 \%$ CI [0.132, 0.412]. Moreover, each CAPE domain was also positively and moderately related to COVID-19 Conspiracy Theories Beliefs, namely CAPE Bizarre Experiences, $r(436)=0.227, p<0.001,99 \%$ CI $[0.090,0.360]$, CAPE Persecutory Ideation, $r(436)=0.223, p<0.001,99 \%$ CI $[0.086$, 0.365], and CAPE Perceptive Abnormalities, $r(436)=0.271, p<0.001,99 \%$ CI [0.071, $0.451]$.

Besides psychotic-like experiences, there were also a marginally significant positive and small association between COVID-19 Conspiracy Theories Beliefs and PANAS Negative score, $r(436)=0.120, p=0.024,99 \%$ CI [- 0.010, 0.255], meaning that negative affect may be linked to beliefs in COVID-19 Conspiracy Theories. Higher QRE Cognitive Reappraisal was also marginally associated with COVID-19 Conspiracy Theories Beliefs, $r$ $(436)=0.117, p=0.017,99 \%$ CI $[-0.005,0.244]$.

[INSERT TABLE 5 HERE]

\section{Control Analysis: Time of questionnaire completion and government-imposed lockdown}

As data collection lasted around 2 months, participants completed the questionnaire in different stages of government-imposed restrictions to manage the pandemic: during the emergency state (until the 2 nd of May; $n=285$ ) and post-emergency state (started on the 3rd of May; $\mathrm{n}=153$ ). The emergency state in Portugal started on the 22nd of March. During this state, the government imposed a lockdown where citizens saw some of their rights suspended such as: the right to freely move in national and international territories, giving the government control over individual circulation. Citizens still had the right to move for professional purposes, healthcare, taking care of others and getting food supplies. This law 
had other implications such as cult freedom, private economic initiative control and resistance right, in this last one, citizens were not allowed to resist government policies. (e.g., the government was allowed to implement movement restrictions, such as prevented people from travelling outside their local area, or leaving home without a "reasonable excuse", being work related or taking care of others). The emergency state was renovated 2 times, until the 2nd of May. The post-emergency state (calamity) started with a "deconfinement" plan composed of three phases, 4th of May, 18th of May and 1st of June. During this time citizens still had several restrictions in Portugal, but now they could already move freely as long as preventive strategies to reduce disease spreading were fulfilled. Telework was applied to everyone who gathered all the requirements to work from home. There were restrictions in public transportation ( $2 / 3$ of the occupation), stores could only take five persons per square meter and there was a mandatory use of mask. Thus, it was important to test whether our variables of interest were influenced by the timing when participants completed the questionnaire (during vs. post-emergency state). The major finding in this analysis was a trend for statistically significant differences between timepoints regarding COVID-19 Conspiracy Theories Beliefs questionnaire, $t(436)=2.718, p=0.013$, MD 99\% CI [-0.18, 5.163]. During the emergency state, participants displayed higher scores in the COVID-19 Conspiracy Theories Beliefs questionnaire in comparison to the post-emergency state period $(\mathrm{M}=22.46, \mathrm{SD}=10.51$ vs. $\mathrm{M}=19.80, \mathrm{SD}=9.51$, respectively $)$. Similarly, COVID-19 related financial concerns were significantly different between both stages, $t(436)=2.800, p$ $=0.004, \mathrm{MD} 99 \% \mathrm{CI}[0.040,0.856]$, as participants displayed higher financial concerns during the emergency state then post-emergency state $(M=4.36, S D=1.73$ vs. $M=3.90, S D$ $=1.64$, respectively). Thus, the timing for completion (during vs. post-emergency state) was also added to the subsequently tested regression model.

\section{Regression Model for Predictors of COVID-19 Conspiracy Theories Beliefs}

A regression model was prepared including as predictors all the variables significantly associated with COVID-19 Conspiracy Theories Beliefs in the previous analysis (education years, COVID-related health concerns, pandemic-related financial concerns, CAPE subscales), as well as variables that were only marginally significant (leaving the house, smoking frequency during confinement, pandemic-related budget reductions, QRE Cognitive Reappraisal, PANAS Negative, timing for questionnaire completion).

Before proceeding with the final model, several assumptions were tested. Regarding the normally distributed residuals assumption, standardized residuals displayed an approximately normal distribution (skewness $=1.126$; kurtosis $=1.867$ ). Although Cook's distance did not suggest any influential cases (max. value $=0.099), 2$ participants presented standardized residuals greater than $|4.0|$, suggesting that the regression equation did not accurately predict the dependent variable for these cases. Thus, these subjects were excluded from the analysis. The independence of errors assumption was not violated (Durbin-Watson statistic $=2.029$ ). Furthermore, there was no evidence of collinearity (highest correlation between predictors was 0.577 ) or multicollinearity (lowest tolerance value was 0.535 ). Finally, the scatter plot with absolute standardized residuals by standardized predicted values suggested some degree of heteroscedasticity, which was further validated by the Koenker test, $\chi^{2}(12)=38.105, p<0.001$. Thus, the regression model was ran using the wild bootstrap, which does not assume homoscedasticity [58,59]. 
Results from the final regression model are presented in Table 6. A significant regression equation was found, $\mathrm{F}(12,423)=8.931, p<0.001$, with an $\mathrm{R} 2$ of 0.202 . Education years was a significant predictor of COVID-19 Conspiracy Theories Beliefs, $\mathrm{B}=-0.510, p=$ $0.001,99 \%$ CI [-0.854, -0.204], meaning that for each less year of education, the COVID-19 Conspiracy Theories Beliefs score was 0.510 points higher. CAPE Perceptual Abnormalities was also a significant predictor of COVID-19 Conspiracy Theories Beliefs, B = 3.041, $p=$ $0.007,99 \%$ CI $[0.062,5.857]$, while CAPE Persecutory Ideation was only a marginally significant predictor, $\mathrm{B}=0.607, p=0.034,99 \% \mathrm{CI}[-0.158,1.348]$. Other marginally significant predictors included COVID-related health concerns, $\mathrm{B}=0.709, p=0.041,99 \% \mathrm{CI}$ $[-0.067,1.617]$, and smoking frequency during confinement, $\mathrm{B}=1.073, p=0.039,99 \% \mathrm{CI}$ [$0.229,2.359$ ], as well as timing for questionnaire completion, $\mathrm{B}=1.992, p=0.025,99 \% \mathrm{CI}$ [-0.202, 4.227], as completers during the emergency state scored 1.992 points higher in the COVID-19 Conspiracy Theories Beliefs questionnaire in comparison to participants that participated in the study post-emergency state.

\section{[INSERT TABLE 6 HERE]}

\section{Discussion}

Conspiracy theories related to the COVID-19 pandemic have become a worldwide issue that hinders the effectiveness of governments and health authorities in managing the spread of this virus. Thus, understanding which factors may predispose individuals to believe and act on these theories may be extremely useful for policymakers, health professionals and even media outlets, allowing to develop more precise communication strategies and identifying high-risk individuals for non-compliance with disease-preventing measures. The current study aimed to assess how proneness to psychotic-like experiences is related to beliefs regarding conspiracy theories, whilst simultaneously accounting for other psychological outcomes (e.g., mood) as well as other pandemic-related factors (e.g., isolation conditions, health concerns, etc). This is a novel hypothesis for dealing with the current and future pandemics that adds important insights into how the adherence to illogical and erroneous disease-related arguments may be contingent to proneness to psychotic-like experiences.

Most conspiracy theories are not based on credible evidence but rather on inaccurate thoughts and frequently illogical ones. Psychotic experiences enhance the development of these types of thoughts $[27,29,60]$. For instance, Barron et al. [61] suggested that there are positive and direct correlations between the belief in conspiracy theories and schizotypy domains, namely strange beliefs, magical thinking, and reference ideas $[28,41,62,63]$. The current results are in line with this previous evidence as we found positive associations between psychotic-like experiences and beliefs in conspiracy theories related to COVID-19. More specifically, the most highly associated domains were psychotic perpetual abnormalities, followed by persecutory ideation experiences.

According to previous evidence, a stronger relation with persecutory ideation would be expected, since this psychotic domain is widely linked to conspiracy beliefs type of thinking [64]. A recent systematic-review actually identified two major groups of predictors for conspiracy beliefs, those being pathological (e.g., paranoia) or socio-political focus [39]. 
Paranoid tendencies are associated with cognitive bias that negatively influences causal and probabilistic thinking, as well as the flexibility of beliefs [61,65]. Similarly, conspiracy theories have also been associated with highly rigid belief system that are not very permeable to change. Wood, Douglas \& Sutton [66] relate conspiracy beliefs to a broad ideologic system, which justifies any belief associated with it, constituting a base ground to understand and assimilate new social conditions. It seems that beliefs in conspiracy theories follow a single-logic approach, through which beliefs on any given theory constitute a way of sustaining other theories $[67,68]$. Thus, persecutory ideation and belief in conspiracy theories may share an underlying vulnerability for biased thinking styles, which ultimately leads to an increased likelihood of producing inaccurate working models of real-word events, especially when there is information (even if false) supporting these misrepresentations.

Perceptual abnormalities were the psychotic domain more clearly associated with COVID-19 conspiracy theories. Dagnall, Drinkwater, Parker, Denovan. \& Parton. [69] merged perceptual abnormalities into a mixed domain called cognitive-perceptual measures, which were reported through three questionnaires (Schizotypal Personality Questionnaire, Delusions Inventory and The Launay-Slade Hallucination Scale). The authors found that beliefs in conspiracies, within the sub-clinical population, were mostly associated with delusional thinking style, although the pooled cognitive-perceptual factor still explained 32\%. Thus, one can argue that the role of perceptual abnormalities on conspiracy theories may also be mechanistically related to other psychotic-like experiences.

Langdon and Coltheart proposed that there must be some damage to sensory and/or attentional-orienting mechanisms which causes aberrant perception, arguing that this same process underlies not only perceptual abnormalities but also persecutory ideation, bizarre experiences or other types of delusional thinking [70]. Ben-Zeev, Ellington, Swendsen \& Granholm. [71] examined a cognitive model of persecutory ideation that suggested that negative emotions, perceptual anomalies, and recent life events are important predictors of experiencing persecutory ideation. Hence, our results regarding perceptual abnormalities may not be interpreted separately from the complete psychotic architecture, as this domain is intrinsically connected to delusional experiences.

Also, confinement due to the COVID-19 pandemic may have also played a role on the clear association between perceptual abnormalities and beliefs in conspiracy theories. The confinement-related social isolation lead to feelings of loneliness that could increase human agency detection, therefore making people more prone to hear voices or perceive human agency in nonhuman stimuli [72]. As participants were requested to report on psychotic-like experiences during confinement, it is feasible to postulate that these abnormal perceptual experiences were enhanced throughout this period, ultimately leading to a more critical role in the association with beliefs in conspiracy theories.

Besides the clear association between psychotic-like experiences, our work also unveiled additional factors that seem to play a critical role in COVID-19 conspiracy theories. For instance, concern with one's own health was associated with beliefs in conspiracy theories. The lack of effective responses to tackle the pandemic as well as the difficulty in transmitting clear and consistent information regarding a widely unknown disease enhanced feelings of uncertainty and concern in the general population. Consequently, this may potentiate the lack of trust in governmental authorities and the health system, which may 
eventually foster the vulnerabilities that make people believe in conspiracy theories [23]. Evidence suggests that reduced knowledge about any given topic increases the probability for beliefs in conspiracy theories [73-75]. When exposed to highly complex and ambiguous situations, individuals who do not have sufficient knowledge regarding a topic have a tendency to use a heuristic processing to formulate their opinions, which raises the likelihood for conspiracy-related beliefs [76-78]. Consistently, when faced with different perspectives and arguments, individuals tend to use a directional bias to strengthen their pre-existing visions $[79,80]$. The COVID-19 pandemic was an ideal setting to nurture these reasoning processes, especially as several unknown sources of misinformation further added to the uncertainty already inherent to a new wide spreading virus.

Another important although expected finding was the negative association between education levels and beliefs in COVID-19 conspiracy theories. Previous evidence clearly suggests that beliefs in conspiracy theories are positively related to lower analytic thinking, open-mindedness, and consequently, intuitive thinking. Individuals who are less educated tend to attribute agency and intentionality where it does not exist [81-83]. Despite the role of education on beliefs in conspiracy theories being expected, this is particularly relevant during a pandemic outbreak. Decision makers and other critical societal agents should be aware of this issue and implement communication strategies that can be easily understood across all education levels. This approach would be extremely valuable not only to increase knowledge about the virus, the treatment and the required preventive measures, but also to demystify misinformation whenever necessary.

Interestingly, we also found that the timing of response played a role on beliefs in COVID-19 conspiracy theories, as levels were higher during the government mandated emergency state. There are two major factors that may explain these findings. First, in the initial stage of the pandemic information was far more inconsistent, which left more room for the proliferation of conspiracy theories. Secondly, the emergency state in Portugal introduced a wide set of restrictions that led to a lack of structured routine and loss of (in-person) social interaction, which may have consequently played a role on psychological well-being (e.g., loss of motivation, meaning and self-worth) $[28,84,85]$. Taking together, it is easy to understand how these factors, which were most likely at their peak during the emergency state, contributed to feelings of threat and insecurity, increasing the likelihood for beliefs in conspiracy theories [86].

Finally, we also found a positive association between tobacco consumption and beliefs in COVID-19 conspiracy theories. Although the current work is cross-sectional and we cannot infer any sort of causality between constructs, we postulate that it is more likely that the intrinsic vulnerability to believe in conspiracy theories may drive the increase in tobacco consumption and not the other way around. Some authors suggest that nicotine may reduce anxiety and depressive-like behavior [87,88], although this is much more a common sense idea that most people have (i.e., "nicotine reduces the anxiety and stress") [89]. Thus, as suggested by the "self-medication" hypothesis of drug abuse [90-92], accentuated depressive/anxiety symptomatology inherently leads to an increase in tobacco consumption. Moreover, it also fairly well known that tobacco consumption is very high in patients with psychotic disorders [93]. Thus, it is possible to postulate that individuals more likely to believe in conspiracy theories may also display an increased vulnerability for tobacco 
consumption, especially in high stress situations were tobacco is seen by its users as an tool to reduce negative affective states.

There are several limitations regarding the present study. Data collection was conducted using an online survey which ultimately does not allow to represent the whole population, as there are potential participants that do not have access to the Internet and hence could not be recruited. Furthermore, the questionnaire was fairly extensive which might have predisposed participants to be less engaged at times and produce less reliable answer. Most importantly, this cross-sectional study does not allow to establish any sort of causal relationships between the measured constructs. Ideally it would be necessary to assess how psychotic-like experiences evolved across time. Additional longitudinal studies would be valuable to understand how different stages of the pandemic control and government management influence psychotic-like experiences as well as measures related to psychological well-being. Furthermore, it would also be relevant to understand these phenomena in clinical populations, including people diagnosed with psychotic-like disorders. Finally, our initial correlation analysis also indicated a trend for a positive association between beliefs in conspiracy theories and COVID-related budget changes and financial concerns, although these associations were not significant in multiple regression analysis. The working-age population is particularly facing uncertainties and constant concerns due to pandemic-related economic changes, which potentiates negative future perspectives that affect their mental health and well-being [94]. Thus, future studies should further assess how work-related factors may moderate the vulnerability to beliefs in COVID-19 conspiracy theories, psychotic-like experiences and other psychological distress factors, as this likely produces indirect costs that can be lessened through effective social protection systems.

\section{Conclusion}

COVID-19 conspiracy theories are yet another major challenge that governments and policy makers must contemplate when defining strategic directions to manage the current pandemic. The current study suggest that psychotic-like experiences are clearly associated with beliefs in conspiracy theories, particularly perceptual abnormalities and persecutory ideation. Moreover, increased health-related concerns and reduced education levels also seem to be liability factors for valuing these theories. Future studies should further refine the role of psychotic-like experiences on these beliefs and explore additional factors (e.g., financial and work-related factors) that can help us to understand how COVID-19 conspiracy theories have become a major worldwide misinformation source, hindering the transmission of factful and meaningful information to the community.

\section{Methods}

Participants Participants, aged 18 or older, were recruited using a "snowball" approach [95]. Recruitment was only performed after the consent and approval of the Ethics Committee of ESS-P.PORTO. All participants agreed with the electronic consent form, prepared according to the Declaration of Helsinki [96]. The survey was anonymous and the participants did not receive any sort of compensation. A total of 547 participants completed the questionnaire. 
However, only 438 participants were included for the full analysis as we decided to exclude participants who were not in confinement (e.g., due to their profession or any other factor). Non-confined subjects did not fully experience the restrictions related to lockdown which would constitute a major confounding factor in our results. The dataset for the current study can be found at osf.io/c82gs.

Instruments The online survey had an estimated length of 15-20 minutes and included the following: sociodemographic questionnaire (age, sex, education levels, employment status); questions addressing behaviours and events related to the COVID-19 pandemic, including confinement experience; COVID-19 Conspiracy Theories Questionnaire, developed by the research team; control question regarding general conspiracy theories[97]; standardized questionnaires to assess psychotic-like experiences as well as others constructs of interest (e.g., perceived stress, satisfaction with activities, etc). Participants were instructed to provide answers regarding their confinement period (i.e., "since you started your confinement did you experience ..."). Reliability coefficients for the included questionnaires were assessed using Cronbach's alpha and the cut-off criteria defined by Kline [98]: $<0.5$ unacceptable; $\geq 0.5$ and $<0.6$ poor; $\geq 0.6$ and $<0.7$ questionable; $\geq 0.7$ and $<0.8$ adequate/acceptable; $\geq 0.8$ and $<0.9$ good; $\geq 0.9$ excellent. Bellow we provide a more detailed description of each component of the online survey.

Questionnaire for behaviors and events related to the COVID-19 pandemic: a survey developed by the research team to understand confinement-related behaviors (outings during confinement, telework, online social contacts, tobacco and alcohol consumption), beliefs (information about the pandemic, health-related concerns, satisfaction with confinement experience, financial concerns), and conditions (having/not having an infected relative, confined alone or not, caregiver for children and/or elderly, available outdoor spaces, employment status and budget changes). This questionnaire can be found at osf.io/c82gs.

COVID-19 Conspiracy Theories Beliefs Questionnaire: 11-item survey conceived by the research team to assess the degree of belief in conspiracy theories related to COVID-19. Each item refers to a conspiracy theory about the pandemic. An online search was conducted by the research team to identify the most common conspiracy theories that were being debated after the start of the pandemic (e.g., COVID-19 is a biologic weapon created in a laboratory setting, big pharmaceutical companies created COVID-19 to achieve huge profits from vaccines). Each statement was rated on a 7-point Likert scale, ranging from "completely false" (1) to "completely true" (7). A total score was computed by adding the rating for each individual item, with higher scores representing stronger beliefs in COVID-19 conspiracy theories. Cronbach's alpha for this questionnaire indicated good internal consistency $(\alpha=$ 0.886). Furthermore, the COVID-19 Conspiracy Theories Beliefs Questionnaire was highly correlated with ratings of overall belief in conspiracy theories, $r(436)=0.582, p<0.001$, $99 \%$ CI [0.493, 0.658].

Community Assessment of Psychotic Experience (CAPE): self-report questionnaire that assesses the frequency of psychotic-like experiences in the general population [99]. It is composed of 15 items, framed within three domains: persecutory ideation (5 items), bizarre experiences ( 7 items), and perceptive abnormalities ( 3 items). Each item is rated on a 4-point Likert scale, with 0 representing "never" and 3 meaning "almost always". Items were summed to compute a total score that can range from 0 to 45 , with higher scores representing 
larger frequency of psychotic experiences. In the current sample, CAPES Total Score displayed good internal consistency $(\alpha=0.867)$. Moreover, the Cronbach's alpha for the CAPE Bizarre Experience also indicated good internal consistency $(\alpha=0.824)$, although internal consistency was only acceptable for CAPE Persecutory Ideation and CAPE Perceptive Abnormalities ( $\alpha=0.773$ and $\alpha=0.766$, respectively).

Perceived Stress Scale (PSS): 13-item questionnaire to assess self-perceived global stress, that is, how frequently certain life events might induce stress [100,101]. Each item is rated on a 5-point Likert scale, ranging from "never" to "many times". In the current sample, Cronbach's alpha for the PSS indicated good internal consistency $(\alpha=0.870)$;

Emotional Regulation Survey (ERS): 10-tem questionnaire to assess the degree to each any given individual uses certain strategies to regulate his/her emotions, namely cognitive reappraisal and expressive suppression strategies which are scored separately [102,103]. Each item is rated on a 7-point Likert scale, ranging from "I totally disagree" to "I totally agree". In the current sample, Cronbach's alpha was poor for the Cognitive Reappraisal domain $(\alpha=$ $0.532)$ and unacceptable for the Expressive Suppression $(\alpha=0.426)$. Thus, results regarding this questionnaire should be interpreted with caution.

Personal Well-Being Index (PWBI): 8-item self-report survey to measure subjective wellbeing, which is achieved by assessing individuals' satisfaction regarding several life domains (e.g., health, life goals, safety, future, spiritual connection, etc) [104]. Each question is rated from 0 to 10, with 0 corresponding to "Totally unsatisfied" and 10 representing "Totally satisfied". In the current sample, Cronbach's alpha for the PWBI indicated good internal consistency $(\alpha=0.858)$;

Activities Questionnaire: 4-items developed by the research team to assess participation and satisfaction regarding productive, leisure, and self-care activities during confinement. Each item was rated using a 7-point Likert scale, ranging from "totally disagrees" to "totally agrees". In the current sample, internal consistency for this questionnaire was acceptable $(\alpha=$ $0.730)$.

Positive and Negative Affect Schedule (PANAS): 10-item self-report measure assessing positive and negative affective states (5 items for each domain) [105]. Each item is rated on a 5-point Likert scale and a total score is computed for each domain. In the current sample, internal consistency was acceptable for the PANAS Positive domain $(\alpha=0.769)$ and good for the PANAS Negative domain $(\alpha=0.840)$.

Three-Item Loneliness Scale: a scale constituted by 3 items, which goal is to quantitatively assess the isolation/loneliness, encompassing the following dimensions: relational connection, social connection, and self-perception of isolation. This is scored using a Liker scale with three answer categories, namely: almost never/never ( 1 point), sometimes ( 2 points), and frequently/always ( 3 points). The final score results from the addition of the score attributed to each answer. The highest the score, the highest the degree of isolation/loneliness $[106,107]$. In the current sample, internal consistency for this questionnaire was acceptable $(\alpha=0.739)$.

Satisfaction, Alertness, Timing, Efficiency and Duration Questionnaire (SATED): self-report measure assessing sleep-related health by considering sleep satisfaction, alert state during 
waking hours, as well as sleep length and efficiency $[108,109]$. This scale includes 6 items, assessed using a 5-point Likert scale. In the current sample, Cronbach's alpha was questionable for this scale $(\alpha=0.695)$.

Statistical analysis Regarding descriptive statistics, absolute and relative frequencies were computed for categorical variables, while mean and standard deviation are reported for continuous variables. For inferential analysis, independent samples t-tests were used to compare several groups (e.g., males vs. females, caregivers vs. non-caregivers during confinement) regarding COVID-19 Conspiracy Theories Beliefs. For this test, the homogeneity of variance assumption was also examined using the Levene's F test. When this assumption was not met, the Welch's t-test was used instead. Pearson correlations were also used to test the association between scores on the COVID-19 Conspiracy Theories Beliefs and other continuous variables (e.g. COVID-19 information levels, confinement experience ratings, scores on other scales). According to the guidelines of Gignac \& Szodorai [110], the magnitude of Pearson correlations were classified as small $(>=0.10)$, moderate $(>=0.20)$, and large $(>=0.30)$. Finally, as the normality assumption was not met for several analysis, bootstrapping (bias corrected accelerated, 1000 samples) was used to estimate test statistics and confidence intervals for the independent samples t-tests and Pearson correlations.

Contingent on the results found in the previous inferential tests, a regression model was prepared including all variables significantly and marginally associated with COVID-19 Conspiracy Theories Beliefs. Before implementing the regression model, the following assumptions were tested: normally distributed residuals (examination of the distribution of standardized residual and identification of influential cases); homoscedasticity (Koenker test and visual inspection of the scatter plot of absolute standardized residuals by standardized predicted values); collinearity (correlation matrix between independent variables); multicollinearity (tolerance and variance inflation factor). The regression model was adjusted after assumption testing, if required. All analysis were implemented using IBM SPSS (version 26). To control for multiple analysis, significance levels were set at 0.01 , although $p$ values between 0.01 and 0.05 were considered as marginally significant. 


\section{References}

1. Marčinko, D., Jakovljević, M., Jakšić, N., Bjedov, S. \& Mindoljević Drakulić, A. The importance of psychodynamic approach during COVID-19 pandemic. Psychiatria Danubina 32, 15-21 (2020).

2. Organization, W.H. Report of the WHO-China Joint Mission on Coronavirus Disease 2019 (COVID-19). in Who.int.

3. Wang, F.S. \& Zhang, C. What to do next to control the 2019-nCoV epidemic? Lancet 395, 391-393 (2020).

4. Habibzadeh, P. \& Stoneman, E.K. The Novel Coronavirus: A Bird's Eye View. Int J Occup Environ Med 11, 65-71 (2020).

5. Organization, W.H. Coronavirus disease 2019 (COVID-19): situation report, 72. (2020).

6. Jakovljevic, M., Bjedov, S., Jaksic, N. \& Jakovljevic, I. COVID-19 pandemia and public and global mental health from the perspective of global health security. Psychiatria Danubina 32, 6-14 (2020).

7. Wang, C., et al. Immediate psychological responses and associated factors during the initial stage of the 2019 coronavirus disease (COVID-19) epidemic among the general population in China. International journal of environmental research and public health 17, 1729 (2020).

8. Chew, Q.H., Wei, K.C., Vasoo, S., Chua, H.C. \& Sim, K. Narrative synthesis of psychological and coping responses towards emerging infectious disease outbreaks in the general population: practical considerations for the COVID-19 pandemic. Singapore medical journal (2020).

9. $\quad$ Shigemura, J., Ursano, R.J., Morganstein, J.C., Kurosawa, M. \& Benedek, D.M. Public responses to the novel 2019 coronavirus (2019-nCoV) in Japan: mental health consequences and target populations. Psychiatry and clinical neurosciences $\mathbf{7 4}, 281$ (2020).

10. Ho, C.S., Chee, C.Y. \& Ho, R.C. Mental health strategies to combat the psychological impact of COVID-19 beyond paranoia and panic. Ann Acad Med Singapore 49, 1-3 (2020).

11. Lei, L., et al. Comparison of Prevalence and Associated Factors of Anxiety and Depression Among People Affected by versus People Unaffected by Quarantine During the COVID-19 Epidemic in Southwestern China. Medical Science Monitor: International Medical Journal of Experimental and Clinical Research 26, e924609924601 (2020).

12. Dong, L. \& Bouey, J. Early Release-Public Mental Health Crisis during COVID-19 Pandemic, China.

13. Brooks, S.K., et al. The psychological impact of quarantine and how to reduce it: rapid review of the evidence. The Lancet (2020).

14. Assari, S. \& Habibzadeh, P. The COVID-19 Emergency Response Should Include a Mental Health Component. Archives of Iranian medicine, 281-282 (2020).

15. Desclaux, A., Badji, D., Ndione, A.G. \& Sow, K. Accepted monitoring or endured quarantine? Ebola contacts' perceptions in Senegal. Social Science \& Medicine 178, 38-45 (2017). 
16. Caleo, G., et al. The factors affecting household transmission dynamics and community compliance with Ebola control measures: a mixed-methods study in a rural village in Sierra Leone. BMC public health 18, 248 (2018).

17. Mian, A. \& Khan, S. Coronavirus: the spread of misinformation. BMC Medicine (2020).

18. Depoux, A., et al. The pandemic of social media panic travels faster than the COVID19 outbreak. J Travel Med 27(2020).

19. Smith, G.D., Ng, F. \& Ho Cheung Li, W. COVID-19: Emerging compassion, courage and resilience in the face of misinformation and adversity. J Clin Nurs 29, 1425-1428 (2020).

20. Mash, H.B.H., Fullerton, C.S. \& Ursano, R.J. Post-traumatic stress symptoms following sniper attacks: Effects of television viewing and identification with victims. Am J Disaster Med 13, 29-36 (2018).

21. Pfefferbaum, B., et al. Disaster media coverage and psychological outcomes: descriptive findings in the extant research. Curr Psychiatry Rep 16, 464 (2014).

22. Kelly, B.D. Plagues, pandemics and epidemics in Irish history prior to COVID-19 (coronavirus): what can we learn? Ir J Psychol Med, 1-6 (2020).

23. Douglas, K.M., Sutton, R.M. \& Cichocka, A. The Psychology of Conspiracy Theories. Curr Dir Psychol Sci 26, 538-542 (2017).

24. Darwin, H., Neave, N. \& Holmes, J. Belief in conspiracy theories. The role of paranormal belief, paranoid ideation and schizotypy. Personality and Individual Differences - PERS INDIV DIFFER 50, 1289-1293 (2011).

25. Stieger, S., Gumhalter, N., Tran, U., Voracek, M. \& Swami, V. Girl in the cellar: a repeated cross-sectional investigation of belief in conspiracy theories about the kidnapping of Natascha Kampusch. Front Psychol 4(2013).

26. van Elk, M. Perceptual Biases in Relation to Paranormal and Conspiracy Beliefs. PLoS One 10, e0130422 (2015).

27. Mækelæ, M.J., Moritz, S. \& Pfuhl, G. Are Psychotic Experiences Related to Poorer Reflective Reasoning? Front Psychol 9, 122-122 (2018).

28. Swami, V., Voracek, M., Stieger, S., Tran, U.S. \& Furnham, A. Analytic thinking reduces belief in conspiracy theories. Cognition 133, 572-585 (2014).

29. McLean, B.F., Mattiske, J.K. \& Balzan, R.P. Association of the Jumping to Conclusions and Evidence Integration Biases With Delusions in Psychosis: A Detailed Meta-analysis. Schizophr Bull 43, 344-354 (2017).

30. Buchy, L., Woodward, T.S. \& Liotti, M. A cognitive bias against disconfirmatory evidence (BADE) is associated with schizotypy. Schizophr Res 90, 334-337 (2007).

31. Linscott, R.J. \& van Os, J. An updated and conservative systematic review and metaanalysis of epidemiological evidence on psychotic experiences in children and adults: on the pathway from proneness to persistence to dimensional expression across mental disorders. Psychological Medicine 43, 1133-1149 (2013).

32. Fonseca Pedrero, E. \& Debbane, M. Schizotypal traits and psychotic-like experiences during adolescence: An update. Psicothema 29, 5-17 (2017).

33. Seiler, N., Nguyen, T., Yung, A. \& O'Donoghue, B. Terminology and assessment tools of psychosis: A systematic narrative review. Psychiatry Clin Neurosci 74, 226246 (2020).

34. Demmin, D.L., DeVylder, J.E. \& Hilimire, M.R. Screening for sub-threshold psychotic experiences and perceived need for psychological services. Early Interv Psychiatry 11, 139-146 (2017). 
35. Fonville, L., et al. MRI Indices of Cortical Development in Young People With Psychotic Experiences: Influence of Genetic Risk and Persistence of Symptoms. Schizophrenia Bulletin 45, 169-179 (2018).

36. van Os, J. \& Reininghaus, U. Psychosis as a transdiagnostic and extended phenotype in the general population. World Psychiatry 15, 118-124 (2016).

37. Kaymaz, N., et al. Do subthreshold psychotic experiences predict clinical outcomes in unselected non-help-seeking population-based samples? A systematic review and meta-analysis, enriched with new results. Psychol Med 42, 2239-2253 (2012).

38. Bentall, R.P., et al. From adversity to psychosis: pathways and mechanisms from specific adversities to specific symptoms. Soc Psychiatry Psychiatr Epidemiol 49, 1011-1022 (2014).

39. Goreis, A. \& Voracek, M. A Systematic Review and Meta-Analysis of Psychological Research on Conspiracy Beliefs: Field Characteristics, Measurement Instruments, and Associations With Personality Traits. Front Psychol 10, 205-205 (2019).

40. Freeman, D. \& Bentall, R.P. The concomitants of conspiracy concerns. Soc Psychiatry Psychiatr Epidemiol 52, 595-604 (2017).

41. Barron, D., Morgan, K., Towell, T., Altemeyer, B. \& Swami, V. Associations between schizotypy and belief in conspiracist ideation. Personality and Individual Differences 70, 156-159 (2014).

42. Kahn-Greene, E.T., Killgore, D.B., Kamimori, G.H., Balkin, T.J. \& Killgore, W.D. The effects of sleep deprivation on symptoms of psychopathology in healthy adults. Sleep Med 8, 215-221 (2007).

43. Bentall, R.P., Wickham, S., Shevlin, M. \& Varese, F. Do specific early-life adversities lead to specific symptoms of psychosis? A study from the 2007 the Adult Psychiatric Morbidity Survey. Schizophr Bull 38, 734-740 (2012).

44. Raihani, N.J. \& Bell, V. Conflict and cooperation in paranoia: a large-scale behavioural experiment. Psychol Med 48, 1523-1531 (2018).

45. Bennett, J.C., Surkan, P.J., Moulton, L.H., Fombonne, E. \& Melchior, M. Childhood social isolation and psychotic experiences in young adulthood: a community based study. Eur Child Adolesc Psychiatry (2019).

46. Boyda, D., McFeeters, D. \& Shevlin, M. Intimate partner violence, sexual abuse, and the mediating role of loneliness on psychosis. Psychosis 7, 1-13 (2015).

47. Michalska da Rocha, B., Rhodes, S., Vasilopoulou, E. \& Hutton, P. Loneliness in Psychosis: A Meta-analytical Review. Schizophr Bull 44, 114-125 (2018).

48. de Sousa, P., Spray, A., Sellwood, W. \& Bentall, R.P. 'No man is an island'. Testing the specific role of social isolation in formal thought disorder. Psychiatry Res $\mathbf{2 3 0}$, 304-313 (2015).

49. Fusar-Poli, P., et al. Deconstructing vulnerability for psychosis: Meta-analysis of environmental risk factors for psychosis in subjects at ultra high-risk. Eur Psychiatry 40, 65-75 (2017).

50. Kirli, U., et al. DSM outcomes of psychotic experiences and associated risk factors: 6-year follow-up study in a community-based sample. Psychol Med 49, 1346-1356 (2019).

51. DeVylder, J.E., Lehmann, M. \& Chen, F.P. Social and clinical correlates of the persistence of psychotic experiences in the general population. Schizophr Res 169, 286-291 (2015).

52. Yates, K., et al. Association of Psychotic Experiences With Subsequent Risk of Suicidal Ideation, Suicide Attempts, and Suicide Deaths: A Systematic Review and Meta-analysis of Longitudinal Population Studies. JAMA Psychiatry 76, 180-189 (2019). 
53. Honings, S., Drukker, M., Groen, R. \& van Os, J. Psychotic experiences and risk of self-injurious behaviour in the general population: a systematic review and metaanalysis. Psychol Med 46, 237-251 (2016).

54. Kelleher, I., et al. Psychotic experiences in the population: Association with functioning and mental distress. Schizophr Res 165, 9-14 (2015).

55. Oh, H., Koyanagi, A., Kelleher, I. \& DeVylder, J. Psychotic experiences and disability: Findings from the Collaborative Psychiatric Epidemiology Surveys. Schizophr Res 193, 343-347 (2018).

56. Oh, H., Waldman, K., Stickley, A., DeVylder, J.E. \& Koyanagi, A. Psychotic experiences and physical health conditions in the United States. Comprehensive Psychiatry 90, 1-6 (2019).

57. Kelleher, I., et al. Prevalence of psychotic symptoms in childhood and adolescence: a systematic review and meta-analysis of population-based studies. Psychol Med 42, 1857-1863 (2012).

58. $\mathrm{Wu}, \mathrm{C} .-\mathrm{F} . J$. Jackknife, bootstrap and other resampling methods in regression analysis. the Annals of Statistics 14, 1261-1295 (1986).

59. Flachaire, E. Bootstrapping heteroskedastic regression models: wild bootstrap vs. pairs bootstrap. Computational Statistics \& Data Analysis 49, 361-376 (2005).

60. Andrade, G. Medical conspiracy theories: cognitive science and implications for ethics. Med Health Care Philos, 1-14 (2020).

61. Barron, D., et al. The relationship between schizotypal facets and conspiracist beliefs via cognitive processes. Psychiatry research 259, 15-20 (2018).

62. Van Der Tempel, J. \& Alcock, J.E. Relationships between conspiracy mentality, hyperactive agency detection, and schizotypy: Supernatural forces at work? Personality and Individual Differences 82, 136-141 (2015).

63. March, E. \& Springer, J. Belief in conspiracy theories: The predictive role of schizotypy, Machiavellianism, and primary psychopathy. PLoS One 14, e0225964 (2019).

64. Joseph, S.M. \& Siddiqui, W. Delusional Disorder. in StatPearls (@) 2020, StatPearls Publishing LLC., Treasure Island FL, 2020).

65. Freeman, D., et al. Coronavirus Conspiracy Beliefs, Mistrust, and Compliance with Government Guidelines in England. Psychological Medicine, 1-30 (2020).

66. Wood, M.J., Douglas, K.M. \& Sutton, R.M. Dead and Alive:Beliefs in Contradictory Conspiracy Theories. Social Psychological and Personality Science 3, 767-773 (2012).

67. Galliford, N. \& Furnham, A. Individual difference factors and beliefs in medical and political conspiracy theories. Scandinavian journal of psychology 58, 422-428 (2017).

68. Swami, V., et al. Conspiracist ideation in Britain and Austria: Evidence of a monological belief system and associations between individual psychological differences and real-world and fictitious conspiracy theories. British Journal of Psychology 102, 443-463 (2011).

69. Dagnall, N., Drinkwater, K., Parker, A., Denovan, A. \& Parton, M. Conspiracy theory and cognitive style: a worldview. Front Psychol 6, 206 (2015).

70. Langdon, R. \& Coltheart, M. The Cognitive Neuropsychology of Delusions. Mind \& Language 15, 184-218 (2000).

71. Ben-Zeev, D., Ellington, K., Swendsen, J. \& Granholm, E. Examining a cognitive model of persecutory ideation in the daily life of people with schizophrenia: a computerized experience sampling study. Schizophr Bull 37, 1248-1256 (2011). 
72. Epley, N., Akalis, S., Waytz, A. \& Cacioppo, J.T. Creating social connection through inferential reproduction: loneliness and perceived agency in gadgets, gods, and greyhounds. Psychological science 19, 114-120 (2008).

73. Nyhan, B. Why the" death panel" myth wouldn't die: Misinformation in the health care reform debate. in The Forum, Vol. 8 (De Gruyter, 2010).

74. Warner, B.R. \& Neville-Shepard, R. Echoes of a conspiracy: Birthers, truthers, and the cultivation of extremism. Communication Quarterly 62, 1-17 (2014).

75. Lukić, P., Žeželj, I. \& Stanković, B. How (ir) rational is it to believe in contradictory conspiracy theories? Europe's journal of psychology 15, 94 (2019).

76. Lupia, A., McCubbins, M.D. \& Arthur, L. The democratic dilemma: Can citizens learn what they need to know?, (Cambridge University Press, 1998).

77. Gilens, M. Political ignorance and collective policy preferences. American Political Science Review, 379-396 (2001).

78. Kuklinski, J.H. \& Quirk, P.J. Reconsidering the rational public: Cognition, heuristics, and mass opinion. Elements of reason: Cognition, choice, and the bounds of rationality, 153-182 (2000).

79. Kahneman, D., Frederick, S., Holyoak, K. \& Morrison, R. The Cambridge handbook of thinking and reasoning. (2005).

80. Taber, C.S. \& Lodge, M. Motivated skepticism in the evaluation of political beliefs. American journal of political science 50, 755-769 (2006).

81. Douglas, K.M., Sutton, R.M., Callan, M.J., Dawtry, R.J. \& Harvey, A.J. Someone is pulling the strings: Hypersensitive agency detection and belief in conspiracy theories. Thinking \& Reasoning 22, 57-77 (2016).

82. Ståhl, T. \& Van Prooijen, J.-W. Epistemic rationality: Skepticism toward unfounded beliefs requires sufficient cognitive ability and motivation to be rational. Personality and Individual Differences 122, 155-163 (2018).

83. Van Prooijen, J.-W. The psychology of conspiracy theories, (Routledge, 2018).

84. Dubey, S., et al. Psychosocial impact of COVID-19. Diabetes \& Metabolic Syndrome: Clinical Research \& Reviews (2020).

85. Williams, S.N., Armitage, C.J., Tampe, T. \& Dienes, K. Public perceptions and experiences of social distancing and social isolation during the COVID-19 pandemic: a UK-based focus group study. BMJ open 10, e039334 (2020).

86. DiGrazia, J. The social determinants of conspiratorial ideation. Socius $\mathbf{3}$, 2378023116689791 (2017).

87. Xiao, X., Shang, X., Zhai, B., Zhang, H. \& Zhang, T. Nicotine alleviates chronic stress-induced anxiety and depressive-like behavior and hippocampal neuropathology via regulating autophagy signaling. Neurochemistry international 114, 58-70 (2018).

88. Choi, D., Ota, S. \& Watanuki, S. Does cigarette smoking relieve stress? Evidence from the event-related potential (ERP). International Journal of Psychophysiology $\mathbf{9 8 ,}$ 470-476 (2015).

89. Lawless, M.H., Harrison, K.A., Grandits, G.A., Eberly, L.E. \& Allen, S.S. Perceived stress and smoking-related behaviors and symptomatology in male and female smokers. Addict Behav 51, 80-83 (2015).

90. Robinson, J., Sareen, J., Cox, B.J. \& Bolton, J. Self-medication of anxiety disorders with alcohol and drugs: Results from a nationally representative sample. Journal of Anxiety Disorders 23, 38-45 (2009).

91. Chilcoat, H.D. \& Breslau, N. Posttraumatic Stress Disorder and Drug Disorders: Testing Causal Pathways. Archives of General Psychiatry 55, 913-917 (1998). 
92. Henningfield, J.E., Smith, T.T., Kleykamp, B.A., Fant, R.V. \& Donny, E.C. Nicotine self-administration research: the legacy of Steven R. Goldberg and implications for regulation, health policy, and research. Psychopharmacology 233, 3829-3848 (2016).

93. Sagud, M., Mihaljevic Peles, A. \& Pivac, N. Smoking in schizophrenia: recent findings about an old problem. Current opinion in psychiatry 32, 402-408 (2019).

94. Creed, P.A. \& Klisch, J. Future outlook and financial strain: testing the personal agency and latent deprivation models of unemployment and well-being. Journal of occupational health psychology 10, 251 (2005).

95. Bindah, E.V. Adoption of Snowball Sampling Technique in an Exploratory Study of Disabled Entrepreneurship, (SAGE Publications Ltd, 2019).

96. Mundial, A.G.d.A.M. Declaração de Helsínquia da Associação Médica Mundial. Fortaleza: Associação Médica Mundial (2013).

97. Lantian, A., Muller, D., Nurra, C. \& Douglas, K. Measuring Belief in Conspiracy Theories: Validation of a French and English Single-Item Scale. Revue Internationale de Psychologie Sociale 29, 1-14 (2016).

98. Kline, R. Principles and Practice of Structural Equation Modeling, 4th Edn New York. NY: The Guilford Press.[Google Scholar] (2016).

99. Brenner, K., et al. Validation of the English and French versions of the Community Assessment of Psychic Experiences (CAPE) with a Montreal community sample. Schizophrenia Research 95, 86-95 (2007).

100. Trigo, M., Canudo, N., Branco, F. \& Silva, D. Psychometric proprieties of the Perceived Stress Scale (PSS) in Portuguese population. Psychologica, 353-378 (2010).

101. Cohen, S., Kamarck, T. \& Mermelstein, R. A global measure of perceived stress. Journal of health and social behavior, 385-396 (1983).

102. Gross, J.J. \& John, O.P. Individual differences in two emotion regulation processes: implications for affect, relationships, and well-being. Journal of personality and social psychology 85, 348 (2003).

103. Vaz, F.M., Martins, C. \& Martins, E.C. Diferenciação emocional e regulação emocional em adultos portugueses. Psicologia 22, 123-135 (2008).

104. Ribeiro, J.P. \& Cummins, R. O bem-estar pessoal: estudo de validação da versão portuguesa da escala. in Actas do $7^{\circ}$ congresso nacional de psicologia da saúde. Lisboa: Ispa 505-508 (2008).

105. Galinha, I.C. \& Pais-Ribeiro, J.L. Contribuição para o estudo da versão portuguesa da Positive and NegativeAffect Schedule (PANAS): II-Estudo psicométrico. Análise psicológica 23, 219-227 (2005).

106. Hughes, M.E., Waite, L.J., Hawkley, L.C. \& Cacioppo, J.T. A Short Scale for Measuring Loneliness in Large Surveys: Results From Two Population-Based Studies. Res Aging 26, 655-672 (2004).

107. Russell, D., Peplau, L.A. \& Cutrona, C.E. The revised UCLA Loneliness Scale: concurrent and discriminant validity evidence. J Pers Soc Psychol 39, 472-480 (1980).

108. Dalmases, M., et al. Impact of sleep health on self-perceived health status. Scientific reports 9, 1-7 (2019).

109. Martins, R.I.S. Validação da Escala de Saúde do Sono (SATED) para a população adulta portuguesa. (2017).

110. Gignac, G.E. \& Szodorai, E.T. Effect size guidelines for individual differences researchers. Personality and individual differences 102, 74-78 (2016). 


\section{Author contributions statement}

Conceptualization: NR, EFP, CC, SR; Methodology: NR, SF, CC, EFP, SR; Data collection: SF and BM; Data curation and analysis: $\mathrm{CC}$ and SF; Original draft, review and editing: All authors.

\section{Acknowledgments}

The authors thank Bruna Vasconcelos (School of Health, Polytechnic Institute of Porto) for assisting with data collection. 
Table 1. Sample characteristics $(n=438)$

\begin{tabular}{ccc}
\hline & Mean \pm SD & Min - Max \\
\hline Age & $34.79 \pm 14.41$ & $18-83$ \\
\hline Education Years & $15.20 \pm 3.54$ & $1-25$ \\
\hline Sex & Groups & $\mathbf{n}(\%)$ \\
\hline \multirow{2}{*}{ Education Level } & Female & $343(78.3 \%)$ \\
\cline { 2 - 3 } & Male & $95(21.7 \%)$ \\
\cline { 2 - 3 } & Elementary School & $2(0.5 \%)$ \\
\cline { 2 - 3 } & Middle School & $10(2.3 \%)$ \\
\hline Employment Status & High School & $127(29 \%)$ \\
\cline { 2 - 3 } (before the pandemic) & College Education & $15(3.4 \%)$ \\
\cline { 2 - 3 } & Unemployed & $61(36.8 \%)$ \\
\cline { 2 - 3 } & Student & $6(1.4 \%)$ \\
\cline { 2 - 3 } & Stay at home & $14(3.2 \%)$
\end{tabular}

Table 2. Confinement Behaviors/Beliefs and COVID-19 Conspiracy Theories $(\mathrm{n}=$ 438)

\begin{tabular}{|c|c|c|c|c|c|c|}
\hline \multicolumn{7}{|c|}{ Group-Comparison } \\
\hline & $\begin{array}{c}\text { Yes } \\
\text { Mean } \pm \text { SD } \\
\text { (n) }\end{array}$ & $\begin{array}{c}\text { No } \\
\text { Mean } \pm \\
\text { SD } \\
\text { (n) }\end{array}$ & $\mathbf{t}$ & $\mathbf{p}$ & $\begin{array}{c}\text { Mean } \\
\text { Difference }\end{array}$ & 99\% CIs \\
\hline $\begin{array}{l}\text { Leaving the } \\
\text { House }\end{array}$ & $\begin{array}{c}21.75 \pm \\
10.37 \\
(\mathrm{n}=409) \\
\end{array}$ & $\begin{array}{c}18.48 \pm \\
7.56 \\
(\mathrm{n}=29)\end{array}$ & $2 . \overline{2}$ & 0.025 & -3.265 & $\begin{array}{c}{[-6.982} \\
0.638]\end{array}$ \\
\hline \multicolumn{7}{|c|}{ Correlation Analysis } \\
\hline \multirow{2}{*}{\multicolumn{3}{|c|}{ Confinement Rating }} & $\mathbf{r}$ & $\mathbf{p}$ & \multicolumn{2}{|c|}{$99 \%$ CIs } \\
\hline & & & 0.034 & 0.596 & \multicolumn{2}{|c|}{$[-0.121,0.196]$} \\
\hline \multicolumn{3}{|c|}{ COVID-Related Health Concerns } & 0.158 & 0.003 & \multicolumn{2}{|c|}{$[0.012,0.292]$} \\
\hline \multicolumn{3}{|c|}{ COVID-Related Information Levels } & $\begin{array}{c}- \\
0.091 \\
\end{array}$ & 0.143 & \multicolumn{2}{|c|}{$[-0.244,0.076]$} \\
\hline \multicolumn{3}{|c|}{$\begin{array}{r}\text { Smoking Frequency During } \\
\text { Confinement }\end{array}$} & 0.129 & 0.024 & \multicolumn{2}{|c|}{$[-0.014,0.273]$} \\
\hline \multicolumn{3}{|c|}{$\begin{array}{r}\text { Alcohol Consumption During } \\
\text { Confinement }\end{array}$} & 0.052 & 0.387 & \multicolumn{2}{|c|}{$[-0.085,0.193]$} \\
\hline
\end{tabular}


Table 3. Confinement Conditions and COVID-19 Conspiracy Theories $(\mathrm{n}=438)$

\begin{tabular}{|c|c|c|c|c|c|c|}
\hline \multicolumn{7}{|c|}{ Group-Comparison } \\
\hline & $\begin{array}{c}\text { Yes } \\
\text { Mean } \pm \text { SD } \\
(\mathrm{n})\end{array}$ & $\begin{array}{c}\text { No } \\
\text { Mean } \pm \\
\text { SD } \\
\text { (n) }\end{array}$ & $\mathbf{t}$ & $\mathbf{p}$ & $\begin{array}{c}\text { Mean } \\
\text { Difference }\end{array}$ & 99\% CIs \\
\hline $\begin{array}{l}\text { Living } \\
\text { Alone }\end{array}$ & $\begin{array}{c}24.49 \pm \\
14.17 \\
(n=35)\end{array}$ & $\begin{array}{c}21.28 \pm \\
9.80 \\
(\mathrm{n}=403) \\
\end{array}$ & -1.302 & $0.213^{*}$ & -3.210 & $\begin{array}{c}{[-10.706,} \\
2.87]\end{array}$ \\
\hline $\begin{array}{l}\text { House with } \\
\text { Outdoors } \\
\text { Space } \\
\end{array}$ & $\begin{array}{c}21.74 \pm \\
10.21 \\
(n=330) \\
\end{array}$ & $\begin{array}{c}20.91 \pm \\
10.33 \\
(n=108) \\
\end{array}$ & -0.735 & 0.458 & -0.829 & $\begin{array}{c}{[-4.061} \\
2.354]\end{array}$ \\
\hline $\begin{array}{c}\text { Family } \\
\text { Member } \\
\text { with } \\
\text { COVID-19 }\end{array}$ & $\begin{array}{c}24.10 \pm \\
11.76 \\
(n=59)\end{array}$ & $\begin{array}{c}21.13 \pm \\
9.94 \\
(n=379)\end{array}$ & -1.880 & 0.061 & -2.970 & $\begin{array}{c}{[-7.267,} \\
0.880]\end{array}$ \\
\hline $\begin{array}{l}\text { Caring of } \\
\text { Children }\end{array}$ & $\begin{array}{c}21.93 \pm \\
9.97 \\
(\mathrm{n}=104) \\
\end{array}$ & $\begin{array}{c}21.41 \pm \\
10.33 \\
(\mathrm{n}=334)\end{array}$ & -0.469 & 0.622 & -0.526 & $\begin{array}{c}{[-3.329} \\
2.271]\end{array}$ \\
\hline $\begin{array}{c}\text { Caring of } \\
\text { Elderly }\end{array}$ & $\begin{array}{c}21.95 \pm \\
9.44 \\
(\mathrm{n}=58) \\
\end{array}$ & $\begin{array}{c}21.47 \pm \\
10.36 \\
(n=380) \\
\end{array}$ & -0.369 & 0.705 & -0.480 & $\begin{array}{c}{[-3.875} \\
3.051]\end{array}$ \\
\hline \multicolumn{7}{|c|}{ Correlation Analysis } \\
\hline & & & $\mathbf{r}$ & $\mathbf{p}$ & \multicolumn{2}{|c|}{ 99\% CIs } \\
\hline \multicolumn{3}{|c|}{$\begin{array}{r}\text { Concern for Family Member with } \\
\text { COVID-19** }\end{array}$} & 0.219 & 0.090 & \multicolumn{2}{|c|}{$[-0.163,0.491]$} \\
\hline & \multicolumn{2}{|c|}{ Activities Questionnaire } & 0.073 & 0.153 & \multicolumn{2}{|c|}{$[-0.069,0.193]$} \\
\hline & \multicolumn{2}{|c|}{ 3-item Loneliness Scale } & 0.078 & 0.149 & \multicolumn{2}{|c|}{$[-0.048,0.190]$} \\
\hline & \multicolumn{2}{|c|}{ Sleep Quality (SATED) } & -0.072 & 0.207 & \multicolumn{2}{|c|}{$[-0.234,0.064]$} \\
\hline
\end{tabular}

$* \mathrm{p}$-value corrected due to heterogeneity of variances

$* * n=59$ (only included participants that had a family member with COVID-19) 
Table 4. Work/Finance-Related Variables and COVID-19 Conspiracy Theories

\begin{tabular}{|c|c|c|c|c|c|c|}
\hline \multicolumn{7}{|c|}{ Group-Comparison } \\
\hline & $\begin{array}{c}\text { Yes } \\
\text { Mean } \pm \text { SD } \\
\text { (n) }\end{array}$ & $\begin{array}{c}\text { No } \\
\text { Mean } \pm \\
\text { SD } \\
\text { (n) }\end{array}$ & $\mathbf{t}$ & $\mathbf{p}$ & $\begin{array}{c}\text { Mean } \\
\text { Difference }\end{array}$ & 99\% CIs \\
\hline $\begin{array}{r}\text { Pandemic- } \\
\text { related } \\
\text { unemployment* }\end{array}$ & $\begin{array}{c}31.50 \pm \\
16.28 \\
(\mathrm{n}=12)\end{array}$ & $\begin{array}{c}21.13 \pm \\
9.06 \\
(\mathrm{n}=230) \\
\end{array}$ & -2.165 & $0.070 * *$ & -10.37 & $\begin{array}{c}{[-23.742,} \\
2.661]\end{array}$ \\
\hline Telework* & $\begin{array}{c}20.67 \pm \\
8.67 \\
(\mathrm{n}=165) \\
\end{array}$ & $\begin{array}{c}23.74 \pm \\
11.20 \\
(\mathrm{n}=77) \\
\end{array}$ & 2.120 & 0.036 & 3.074 & $\begin{array}{c}{[-0.507} \\
7.123]\end{array}$ \\
\hline $\begin{array}{r}\text { Pandemic- } \\
\text { related budget } \\
\text { reductions }\end{array}$ & $\begin{array}{c}22.68 \pm \\
10.32 \\
(\mathrm{n}=200) \\
\end{array}$ & $\begin{array}{c}20.57 \pm \\
10.09 \\
(n=238) \\
\end{array}$ & -2.174 & 0.036 & -2.104 & $\begin{array}{c}{[-4.552} \\
0.462]\end{array}$ \\
\hline \multicolumn{7}{|c|}{ Correlation Analysis } \\
\hline & & & $\mathbf{r}$ & $\mathbf{p}$ & \multicolumn{2}{|c|}{ 99\% CIs } \\
\hline \multicolumn{3}{|c|}{ Family budget (before the pandemic) } & -0.041 & 0.352 & \multicolumn{2}{|c|}{$[-0.156,0.066]$} \\
\hline \multicolumn{3}{|c|}{ Pandemic-related financial concerns } & 0.189 & $<0.001$ & \multicolumn{2}{|c|}{$[0.057,0.328]$} \\
\hline \multicolumn{3}{|c|}{$\begin{array}{r}\text { Pandemic-related degree of budget } \\
\text { reductions } * * *\end{array}$} & 0.149 & 0.054 & \multicolumn{2}{|c|}{$[-0.045,0.347]$} \\
\hline
\end{tabular}

$* \mathrm{n}=242$ (only included employed participants before the pandemic)

$* * \mathrm{p}$-value corrected due to heterogeneity of variances

$* * * n=200$ (only included participants that experienced budget reductions) 
Table 5. Clinical Measures, Psychological Distress and COVID-19 Conspiracy Theories

\begin{tabular}{|c|c|c|c|c|c|c|}
\hline \multicolumn{7}{|c|}{ Group-Comparison } \\
\hline & $\begin{array}{c}\text { Yes } \\
\text { Mean } \pm \text { SD } \\
\text { (n) }\end{array}$ & $\begin{array}{c}\text { No } \\
\text { Mean } \pm \text { SD } \\
\text { (n) }\end{array}$ & $\mathbf{t}$ & $\mathbf{p}$ & $\begin{array}{c}\text { Mean } \\
\text { Difference }\end{array}$ & 99\% CIs \\
\hline $\begin{array}{c}\text { Psychiatric } \\
\text { History }\end{array}$ & $\begin{array}{c}22.12 \pm \\
12.73 \\
(\mathrm{n}=34)\end{array}$ & $\begin{array}{c}21.48 \pm \\
10.02 \\
(n=404)\end{array}$ & -0.274 & 0.797 & -0.635 & {$[-7.175,4.365]$} \\
\hline $\begin{array}{c}\text { Psychiatric } \\
\text { Family } \\
\text { History }\end{array}$ & $\begin{array}{c}20.64 \pm 9.12 \\
(n=53)\end{array}$ & $\begin{array}{c}21.65 \pm \\
10.39 \\
(n=385) \\
\end{array}$ & 0.770 & 0.434 & 1.013 & {$[-2.350,4.185]$} \\
\hline $\begin{array}{l}\text { Psychological } \\
\text { Treatment }\end{array}$ & $\begin{array}{c}19.70 \pm 9.39 \\
(n=43)\end{array}$ & $\begin{array}{c}21.73 \pm \\
10.32 \\
(n=395)\end{array}$ & 1.326 & 0.186 & 2.034 & {$[-2.105,5.565]$} \\
\hline \multicolumn{7}{|c|}{ Correlation Analysis } \\
\hline & & & $\mathbf{r}$ & $\mathbf{p}$ & \multicolumn{2}{|c|}{ 99\% CIs } \\
\hline & & APES Total & 0.271 & $<0.001$ & \multicolumn{2}{|c|}{$[0.132,0.412]$} \\
\hline & CAPE Bizarr & Experiences & 0.227 & $<0.001$ & \multicolumn{2}{|c|}{$[0.090,0.360]$} \\
\hline & CAPE Persec & tory Ideation & 0.223 & $<0.001$ & \multicolumn{2}{|c|}{$[0.086,0.365]$} \\
\hline $\mathrm{CA}$ & PE Perceptive & bnormalities & 0.271 & $<0.001$ & \multicolumn{2}{|c|}{$[0.071,0.451]$} \\
\hline & & PSS & -0.010 & 0.848 & \multicolumn{2}{|c|}{$[-0.127,0.121]$} \\
\hline & QRE Cognitiv & Reappraisal & 0.117 & 0.017 & \multicolumn{2}{|c|}{$[-0.005,0.244]$} \\
\hline & QRE Expressiv & Suppression & 0.057 & 0.255 & \multicolumn{2}{|c|}{$[-0.076,0.183]$} \\
\hline & $\mathrm{PA}$ & JAS Positive & -0.021 & 0.681 & \multicolumn{2}{|c|}{$[-0.153,0.103]$} \\
\hline & PAI & AS Negative & 0.120 & 0.024 & \multicolumn{2}{|c|}{$[-0.010,0.255]$} \\
\hline
\end{tabular}


Table 6. Predictor of Beliefs in COVID-19 Conspiracy Theories: Regression Model

\begin{tabular}{|c|c|c|c|c|}
\hline & $\boldsymbol{B}$ & $S E B$ & B $99 \%$ Cis & $\boldsymbol{\beta}$ \\
\hline $\begin{array}{r}\text { Time of questionnaire } \\
\text { completion (During vs. Pos- } \\
\text { Emergency State) }\end{array}$ & 1.992 & 0.867 & {$[-0.202,4.227]$} & $0.096^{*}$ \\
\hline Education Years & -0.510 & 0.130 & $\begin{array}{c}{[-0.854,-} \\
0.204]\end{array}$ & $0.182^{-} * *$ \\
\hline Leaving the House (Yes / No) & 3.043 & 1.728 & {$[-1.229,6.839]$} & 0.077 \\
\hline $\begin{array}{r}\text { COVID-Related Health } \\
\text { Concerns }\end{array}$ & 0.709 & 0.335 & {$[-0.067,1.617]$} & $0.117^{*}$ \\
\hline $\begin{array}{r}\text { Smoking Frequency During } \\
\text { Confinement }\end{array}$ & 1.073 & 0.503 & {$[-0.229,2.359]$} & $0.109 *$ \\
\hline $\begin{array}{r}\text { Pandemic-related financial } \\
\text { concerns }\end{array}$ & 1.300 & 0.878 & {$[-0.899,3.552]$} & 0.066 \\
\hline $\begin{array}{r}\text { Pandemic-related degree of } \\
\text { budget reductions }\end{array}$ & 0.266 & 0.307 & {$[-0.639,1.100]$} & 0.046 \\
\hline CAPE Persecutory Ideation & 0.607 & 0.288 & {$[-0.158,1.348]$} & $0.130 *$ \\
\hline 5CAPE Bizarre Experiences & 0.030 & 0.228 & {$[-0.568,0.675]$} & 0.008 \\
\hline $\begin{array}{r}\text { CAPE Perceptive } \\
\text { Abnormalities } \\
\end{array}$ & 3.041 & 1.224 & {$[0.062,5.857]$} & $0.179 * *$ \\
\hline QRE Cognitive Reappraisal & 0.150 & 0.080 & {$[-0.071,0.327]$} & 0.082 \\
\hline PANAS Negative & -0.064 & 0.125 & {$[-0.360,0.207]$} & -0.028 \\
\hline$R^{2}$ & & & 0.202 & \\
\hline$F$ & & & $8.931 * *$ & \\
\hline
\end{tabular}

${ }^{*} \mathrm{p}<0.05 ; * * \mathrm{p}<0.01$ 